\title{
Awareness and Utilization of Emergency Contraception Among Female High School Students in Southeast Ethiopia
}

\author{
Minilik Siyum $^{1}$ and Abraham Alano ${ }^{2 *}$ \\ ${ }^{1}$ School of public and environmental health, Hawassa University, Hawassa, Ethiopia \\ ${ }^{2}$ College of Medicine and Health Sciences, Hawassa University and Policy Study and Research Institute, SNNPR, Hawassa, \\ Ethiopia
}

*Corresponding author: Abraham Alano, College of Medicine and Health Sciences, Hawassa University and Policy Study and Research Institute, SNNPR, Hawassa, Ethiopia

\section{ARTICLE INFO}

Received: 崑 September 07, 2021

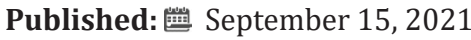

Citation: Minilik Siyum, Abraham Alano. Awareness and Utilization of Emergency Contraception Among Female High School Students in Southeast Ethiopia. Biomed J Sci \& Tech Res 38(5)-2021. BJSTR. MS.ID.006200.

Keywords: Emergency Contraceptive; Awareness; Utilization; Adolescent

Abbreviations: CI: Confidence Interval; EDHS: Ethiopian Demographic Health Survey; EC: Emergency Contraceptive; ECPs: Emergency Contraceptive Pills; IRB: Institutional Reviewing Board; IUCD: Intra Uterine Contraceptive Device; KAP: Knowledge, Attitude and Practice; SPSS: Statistical Package for Social Science

\section{ABSTRACT}

Background: Despite the existence of sound contraceptive methods including emergency contraception, there are huge numbers (84 million) of unplanned pregnancies occurring globally. Fifty percent of these pregnancies ended up in induced abortion out of which, 21 million are unsafely manipulated. Teen age girls are at double risk of the situation. The situation is worse in the developing countries like Ethiopia and much worse in rural and sub urban areas. The paucity of information in most rural part limits interventions that fit to the local situation.

Objective: To assess awareness and utilization of emergency contraception and associated factors among female high school students in Dodola town, Oromia regional state, Ethiopia.

Methods: A cross- sectional quantitative study was conducted using stratified random sampling technique. Data were entered, cleaned and analyzed using SPSS version 20. Bivariate and multivariate logistic regression analyses were conducted to examine the factors associated with the awareness and utilization of emergency contraceptives.

Result: From a total of 773 female students 719 completed the questioners correctly; making the response rate of $93.02 \%$. Four hundred fifty-three (63\%) of the respondents were aged between 13-15 years with the mean age of 15.46(SD +/-1.76). Majority 578(80.4\%) of the study participants were from Oromo ethnic group. About $304(42.3 \%)$ had ever heard the existence of EC and about $9.8 \%$ of sexually active respondents had used it. Awareness of EC was associated with age greater than 15 years $(\mathrm{AOR}=2.92(95 \% \mathrm{CI}(1.99,4.26)]$, having radio $(\mathrm{AOR}=4.43(95 \% \mathrm{CI}(2.64,7.38)]$, having TV $(\mathrm{AOR}=1.99(95 \% \mathrm{CI}(1.19,3.30)]$ and chewing chat $(\mathrm{AOR}=3.08(95 \% \mathrm{CI}(1.39$, 6.82)]. Utilization of EC was associated with age, mothers' educational status and having constant pocket money.

Conclusion and Recommendations: The study revealed that awareness and utilization of emergency contraceptives is low. This leads to increased risk of unintended pregnancy and unsafe abortion. Therefore, the study recommends all concerned bodies should take parts in designing programs which increase the awareness and utilization of EC among high school students.

\section{Plain English Summary}

The long-established contraceptive methods including emergency contraception have not contributed adequately to stop the occurrence of huge numbers of unplanned pregnancies globally. Close to half of these pregnancies ended up in induced abortion 
and significant proportions of it are manipulated unsafely. Teen age girls in developing nations including Ethiopia are at increased risks. The situation is worse in the developing countries like Ethiopia and much worse in rural and sub urban areas. However, the gap in information has been affecting the interventions. Therefore, this study is conducted with the aim to assess the awareness and utilization of emergency contraception and associated factors among female high school students' south-east of the Oromia region, Ethiopia. The study employed a cross- sectional quantitative using stratified random sampling technique. The overall data management and processing used sound statistical software for this purpose. Appropriate statistics were used to reveal statistical associations of related variables to the emergence contraception awareness and utilization. Ninety three percent of the study participants completed the questioners correctly. More than half of the respondent were in the age range between 13-15 years with the mean age of 15.46(SD +/-Majority of the study participants were from Oromo ethnic group. Less than half of the respondents had ever heard the existence of emergency contraceptives. Small proportions of sexually active respondents had used it. The study indicated that awareness and use of emergency contraceptives increase with age and level of education both the students and that of the mothers. The study revealed that awareness and utilization of emergency contraceptives is low. This leads to increased risk of unintended pregnancy and unsafe abortion. Therefore, the study recommends all concerned bodies should take parts in designing programs which increase the awareness and utilization of EC among high school students.

\section{Introduction}

\section{Background}

Emergency contraception (EC) is contraceptive methods that can be used by women within five days following unprotected intercourse to prevent an unplanned pregnancy.EC provide a unique opportunity for preventing pregnancy after unprotected sex that no other contraceptive method can provide. It is as effective as $75-99 \%$ if taken within recommended time frame [1]. The capability of EC addressing the problems of unintended pregnancy in adolescent and young people posits the service one of the most crucial remedies in contraceptive arena for the fact that the sexual activity during adolescence is usually infrequent, unplanned and unprotected [1,2]. Moreover, the steady increase in school attendance rates in developing countries has given the chance for large proportion of young people to become sexually mature while they are at secondary school or earlier. When unintended pregnancy occurred to young girls they forced to dropout from school or goes for unsafe abortion [3]. In connection to the magnitude of the problems, nearly 210 million pregnancies occur each year globally. About $40 \%$ of these pregnancies were unintended. Of these unintended pregnancies 50\% ended in abortion. About 42 million induced abortions each year, nearly 20 million abortions are unsafe. This represents $13 \%$ of maternal death. More than $95 \%$ of unsafe abortions occur in developing countries and nearly half of maternal deaths in sub-Saharan Africa were due to unsafe abortion $[4,5]$. In most developing countries complication of pregnancy and childbirth are a leading cause of death and disability among women of reproductive age. Teenage girls are at double risk of dying from pregnancy and birth complication than women over 20 years. This risk is five times higher for those girls under 15. In sub-Saharan
Africa nearly $60 \%$ of women who have unsafe abortion are younger than 25years of age, and $25 \%$ are teenagers $[5,6]$.

The magnitude of abortion related morbidity and mortality are highest among young unmarried women in developing nations. For instance, in Uganda among women hospitalized with abortion-related complications, about two-thirds were 15 to 19 years old, two-thirds were students, and $80 \%$ of them had never been married. In Nigeria Hospital-based studies have shown that up to $80 \%$ of patients with abortion-related complications are adolescents. In Ethiopia abortion accounts 60\% of gynecological admission and girls under age 15 are three times more likely to end their pregnancies in abortion as compared to those ages 20-24. According to the 2011 Ethiopian Health and Demographic Survey (EDHS), 12\% of young women age 15-19 have already begun childbearing $[1,6,7]$. Study conducted in Nepal among youths of 15-24 years in higher secondary and undergraduate students, the level of awareness of EC found to be $47 \%$. But, only few mentioned the correct definition (17.02\%) and consuming time $(9.58 \%)$ of emergency contraceptive pills (ECP). Similarly, a study done in Dar Es Salaam, Tanzania, revealed that $57 \%$ of the respondents aware of ECP and only $14 \%$ had used it. A study conducted in Dessie, Ethiopia, on knowledge, attitude and practice (KAP) of emergency contraception among female college students disclosed that among those who had history of having sexual intercourse $78.3 \%$ of them faced unwanted pregnancies and $43.3 \%$ of these unwanted pregnancies resulted in abortion.

Of the respondents who had heard about emergency contraception only $15.4 \%$ of them made use of it. A study conducted 
in Jimma town, south west Ethiopia among female high school students revealed that $(40.5 \%)$ had heard about EC. From those who heard of EC, $27 \%$ of the respondents mentioned the correct recommended timing for oral pills of emergency contraception [811]. Currently, there are more adolescent girls in school than ever in our country. It is imperative that these girls have to complete their secondary education and beyond without any risk of unwanted pregnancies. EC is one of the known contraceptive methods to avert such problem. Knowing the level of awareness and utilization of EC by school adolescents is the first step of all the intervention to be implemented to protect adolescents from unintended pregnancy Though few studies have been conducted on EC, they were focused only on students of higher institutions in big cities of the country. However, there are few or no scientific based research has been conducted so far in a district town like Dodola in which students come from both the town and rural areas around it. Thus, this study was conducted with an intention to determine awareness and utilization of EC and factors affecting the awareness and utilization of EC among Dodola female high school students. The study finding aimed to shape the local intervention by equipping district and zonal health leaders and service providers. Furthermore, the finding of the study will enable the comparison of service utilization within the region and outside; hence area specific interventions can be planned.

\section{Methods and Materials}

\section{Study Setting}

Dodola is located in southern part of Ethiopia, Oromia national regional state, west Arsi Zone at distance of $320 \mathrm{~km}$ from the capital city Addis Ababa and $75 \mathrm{~km}$ from Shashemene, the zonal center. According to $2014 \backslash 15$ woreda base plan, Dodola has total population 30,238 of which 14,917 males and 15,321 females. There are two administrative kebeles. With respect to some social services, the town has one district hospital and two health posts owned by the government. Moreover, it has one higher, four medium, six lower clinics, one pharmacy and eleven drug stores owned privately. There are three elementary, one high school and one preparatory public school.

\section{Study Design}

The study employed an institutional based cross-sectional quantitative study design with internal comparison carried out among female high school students in Dodola town, Oromia regional state in January 2016.

\section{Population}

Source Population: The source population of the study includes all high school female students in Dodola town who were enrolled in 2015/16 academic year.

Study Population: The Study populations were female high school students which were randomly selected for the study from both high schools in the town.

\section{Sample Size}

The sample size was determined using the following assumptions: for the first study objective, expected prevalence of level of awareness of EC (64.48\%) [12], Level of confidence 95\%, and $5 \%$ margin of error $(d=0.05)$. Formula for calculating the sample size $n=[(Z 2) \times P(1-P) / D 2]$. Considering design effect of 1.5 and using correction formula for finite population $(\mathrm{N}=1123 \mathrm{female}$ students) by adding nonresponse rate of $10 \%$ the final sample size $=395$. Following similar assumption and formula by taking the prevalence of EC utilization to be (25\%) [11] sample size for the second objective was 344 . However, when adjusted for sexually active students, the sample size increased to 773 . By comparing two sample sizes, the largest 773 was taken as final sample size to ensure the maximum sample size (Figure 1).

\section{Sampling Technique}

The schools were stratified in grade levels (9th\& 10th). Respondents from each section were selected by simple random sampling using school enrollment list as sampling frame. Proportional distribution of sample was assigned to the respective schools, grades and sections based on the enrolment data for the academic year (Figure 2).

\section{Data Collection Procedure \& Quality Management}

The data collection instrument was an anonymous selfadministered structured questionnaire. The questionnaires initially prepared in English and translated to Afan Oromo, and again back to English to ensure consistency and validity by language experts. Five percent of the samples were pretested before the actual data collection and some questions were amended. Training was given for data collection facilitators and supervisors for two days before the pretest and for a day after the pretest. The questionnaires were distributed to randomly selected students. Once the students finished filling the self-administered questionnaires, they had deposited them in a designated box, as informed earlier, to assure their anonymity. The overall data collection process was supervised by Principal investigator. 


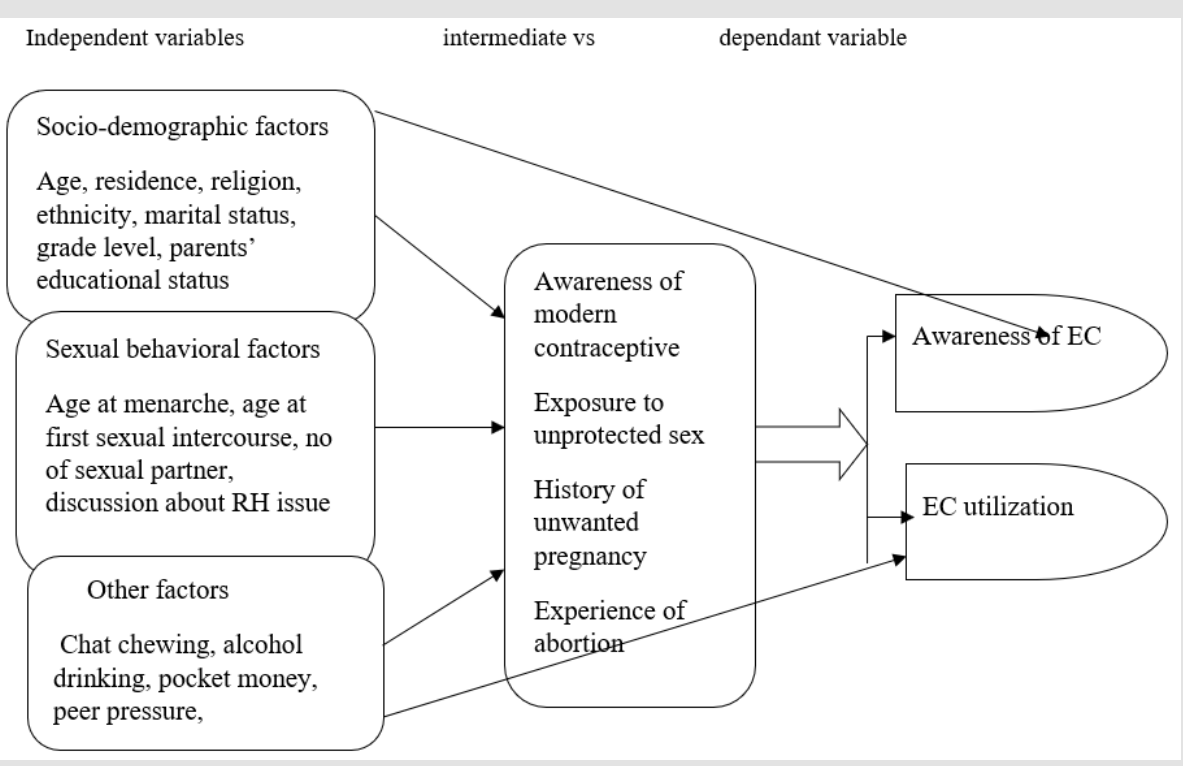

Figure 1: Conceptual framework for EC.

Note: Berhanu Desta and Nigatu Regassa 2011.

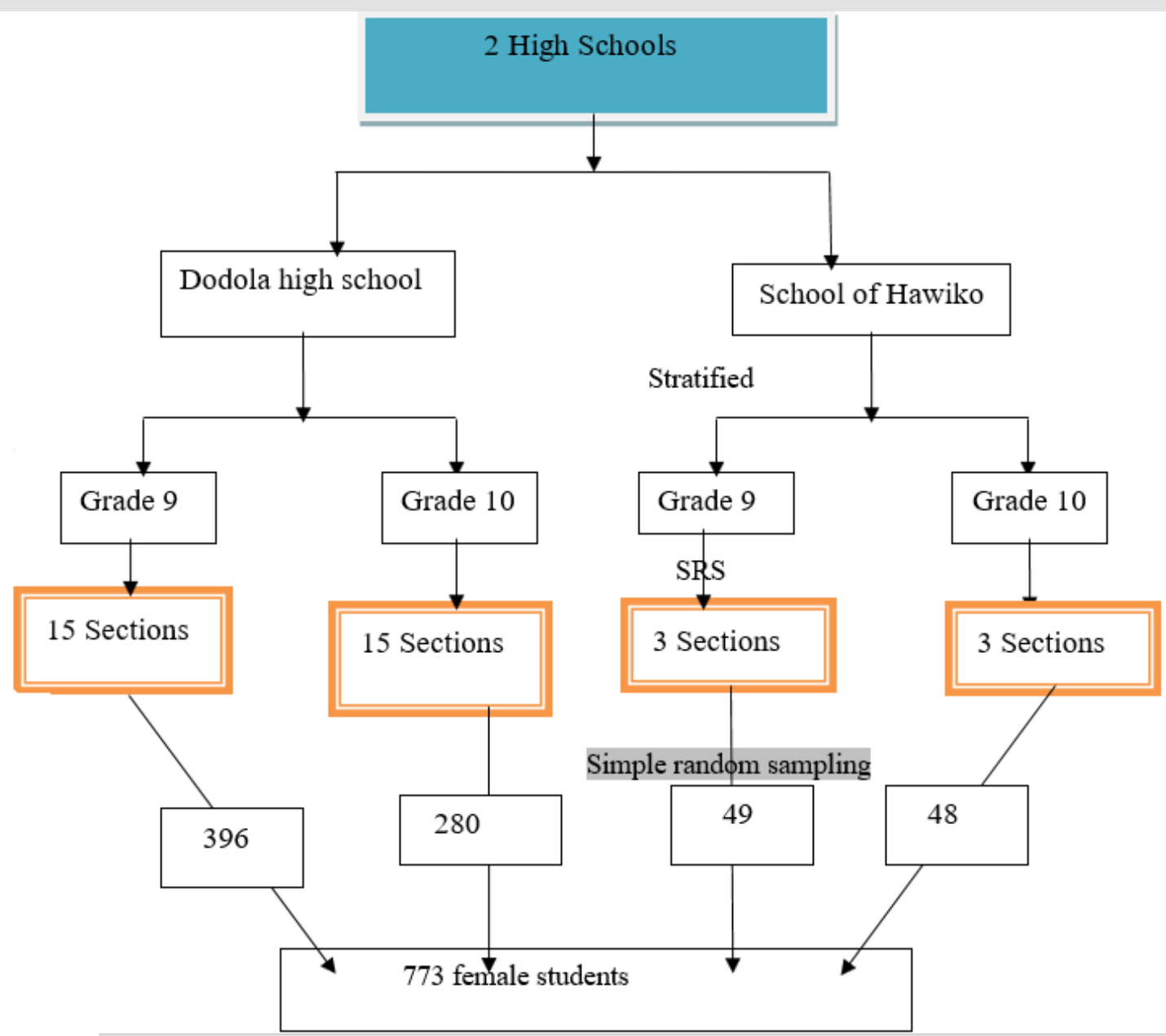

Figure 2: Schematic Presentation of Sampling Technique. 


\section{Operational Definition}

Utilization of Emergency Contraceptives: Ever practice of emergency contraceptives.

Awareness of Emergency Contraceptive: Ever heard the existence of emergency contraceptive.

Unprotected Sexual Intercourse: Sexual intercourse that may result in unintended pregnancy.

\section{Data Processing and Analysis}

The collected data ware checked for their completeness and consistency and entered into SPSS version 20 for analysis. Data was summarized and organized using appropriate descriptive measures; frequencies and percentages of the responses were calculated. Associations between variables were assessed by using Odds Ratio with 95\% Confidence Interval. First all variables were analyzed with bivariate analysis, then variables with p-value less than 0.25 were considered in Multivariate logistic- regression. Statistical association was declared at $p$-value less than 0.05 both in Bivariate and Multivariate logistic-regression.

\section{Result}

\section{Socio-Demographic Characteristics of the Study Population}

Seven hundred nineteen of the total 773 school adolescents were completed the survey questionnaire. Fifty four $(6.98 \%)$ of the questionnaire were discarded due to incompleteness. Majority of the respondents $452(62.9 \%)$ were aged between 13-15 years with the mean age of 15.46 year with standard deviation (SD) of 1.76. About (51.6\%) were attending grade nine and most of the respondents (96.2\%) were single during the survey. The dominant religion was Islam (73.3\%) followed by Orthodox (18.8\%) and the majority were from Oromo ethnic group 578(80.4\%).

\section{Awareness of Respondents on Modern and Emergency Contraceptive}

Table 1: Socio demographic characteristics of female high schools students of Dodola town, January 2016.

\begin{tabular}{|c|c|c|c|}
\hline Characteristics & Response category & Number & Percent \\
\hline \multirow{3}{*}{ Age } & $13-15$ & 453 & 63 \\
\hline & $16-18$ & 211 & 29.1 \\
\hline & $19-21$ & 55 & 7.6 \\
\hline \multirow{3}{*}{ Ethnicity } & Oromo & 578 & 80.4 \\
\hline & Amhara & 103 & 14.3 \\
\hline & others & 38 & 5.3 \\
\hline \multirow{4}{*}{ Religious } & Islam & 527 & 73.3 \\
\hline & Orthodox & 142 & 19.7 \\
\hline & Protestants & 37 & 5.1 \\
\hline & Others & 20 & 2.8 \\
\hline \multirow{3}{*}{ Marital status } & Single & 692 & 96.2 \\
\hline & Married & 26 & 3.6 \\
\hline & Divorced & 1 & 0.1 \\
\hline \multirow{2}{*}{ Grade } & $9^{\text {th }}$ & 401 & 55.8 \\
\hline & $10^{\text {th }}$ & 318 & 44.2 \\
\hline Place of primary & Urban & 382 & 53.1 \\
\hline Education & Rural & 337 & 46.9 \\
\hline Currently living & Parents \husband & 430 & 59.8 \\
\hline \multirow{2}{*}{ With } & Friends & 272 & 37.8 \\
\hline & Alone & 17 & 2.4 \\
\hline
\end{tabular}

Majority of the respondents 692(96.2\%) had ever heard about modern contraceptives but only 304(42.3\%) had ever heard the existence of EC before the survey. From those who ever heard of EC, $65.8 \%$ of them said oral pill should be used within $72 \mathrm{hrs}$ (3days) and $20.4 \%$ of them said Intra uterine Contraceptive Device
(IUCD) should be used within 120hrs (5days) after unprotected sex to prevent unintended pregnancy. Of those who heard of EC, $207(68.1 \%)$ respondents said EC should be used after unprotected sex whereas $90(29.6 \%)$ of them said it should be used after unwanted pregnancy (Table1). 


\section{Utilization of Emergency Contraceptive}

From the total 275 sexually active students only 27(9.8\%) of them had used EC. Oral pill was the only methods utilized as EC.
About $21(77.8 \%)$ of users took the first dose within 72 hours after unprotected sexual intercourse and 17(63\%) of them were recommended to use EC by their female friends. More than eighty five percent of EC users had used it two and more times. (Table 2).

Table 2: Awareness and utilization of female high schools students towards emergency contraception in Dodola town, January 2016.

\begin{tabular}{|c|c|c|}
\hline Characteristics & Number & Percent \\
\hline \multicolumn{3}{|c|}{ Ever heard of modern contraceptive } \\
\hline Yes & 692 & 96.2 \\
\hline No & 27 & 3.8 \\
\hline \multicolumn{3}{|c|}{ Type of modern contraceptive heard** } \\
\hline Pills & 678 & 98 \\
\hline Condom & 671 & 97 \\
\hline inject able & 658 & 95.1 \\
\hline Implanone & 597 & 86.3 \\
\hline IUCD & 581 & 84 \\
\hline Tubal ligation & 270 & 39 \\
\hline Vasectomy & 84 & 12.1 \\
\hline \multicolumn{3}{|c|}{ Ever heard of EC } \\
\hline Yes & 304 & 42.3 \\
\hline No & 415 & 57.7 \\
\hline \multicolumn{3}{|c|}{ Type of EC heard ** } \\
\hline Pills & 304 & 100 \\
\hline IUCD & 169 & 55.6 \\
\hline Other incorrect & 99 & 32.6 \\
\hline \multicolumn{3}{|c|}{ Source of information for EC $* *$} \\
\hline Health professional & 218 & 71.7 \\
\hline Friends & 223 & 73.4 \\
\hline School & 185 & 60.9 \\
\hline Family & 3 & 1 \\
\hline Mass media & 34 & 11.2 \\
\hline Reading material & 10 & 3.3 \\
\hline \multicolumn{3}{|c|}{ Source for EC $* *$} \\
\hline Pharmacy & 290 & 95.4 \\
\hline Private clinics & 293 & 96.4 \\
\hline Governmental health institutions & 284 & 93.4 \\
\hline Shop \& don't know & 11 & 3.6 \\
\hline
\end{tabular}

\section{Determinant Factors Related to the Awareness and Practice of Emergency Contraceptives}

During bivariate logistic regression, age of respondent, having TV, having radio, having constant pocket money, drinking alcoholic beverage, chewing chat, mothers' educational status and place of primary education showed significant association with the awareness of EC. Similarly, age of respondent, grade level, having TV, having constant pocket money, drinking alcoholic beverage and mothers' educational status showed association with utilization of EC when analyzed using bivariate logistic regression. However, multivariate logistic regression analysis indicated that, age $>$ 15years $(\mathrm{AOR}=2.92(95 \% \mathrm{CI}(1.99,4.26)]$, having radio(AOR= 4.42 (95\% CI $(2.64,7.38)]$, having TV(AOR= 1.99(95\% CI $(1.19,3.30)]$ and chewing chat $(\mathrm{AOR}=3.08(95 \% \mathrm{CI}(1.39,6.82)]$ showed statistically significant association with the awareness of EC (Table 3). Likewise, only age $>15$ years $(\mathrm{AOR}=3.52(95 \% \mathrm{CI}(1.04,1.92)]$, having constant pocket money(AOR $=3.52(95 \% \mathrm{CI}(1.15,10.75)]$ and mothers' educational status(AOR $=4(95 \% \mathrm{CI}(1.32,12.09)]$ were remained the real predictors of EC utilization when adjusted to the confounders with multivariate analysis (Tables $3 \& 4$ ). 
Table 3: Bivariate and multivariate logistic regressions of selected variables in relation to awareness of EC among female high school students in Dodola town; January 2016.

\begin{tabular}{|c|c|c|c|c|c|}
\hline \multirow{2}{*}{\multicolumn{2}{|c|}{ Prediction variable }} & \multicolumn{2}{|c|}{ Ever heard EC } & \multirow{3}{*}{$\begin{array}{c}\text { Crude OR(95\%CI) } \\
1 \\
\end{array}$} & \multirow{3}{*}{$\begin{array}{c}\text { Adjusted OR(95\%CI) } \\
1 \\
\end{array}$} \\
\hline & & \multirow{2}{*}{$\begin{array}{c}\text { Yes } \\
164(53.9 \%)\end{array}$} & \multirow{2}{*}{$\begin{array}{c}\text { no } \\
290(69.9 \%) \\
\end{array}$} & & \\
\hline A бe in yeare & $<=15$ & & & & \\
\hline 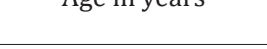 & $>15$ & $140(46.1)$ & $152(30.1)$ & $1.98(1.5,2.7)$ & $2.92(1.99,4.26)^{* * *}$ \\
\hline \multirow{2}{*}{ Having Radio } & Yes & $268(88.2 \%)$ & 238(57.3\%) & $5.54(3.72,8.25)$ & $4.42(2.64,7.38)^{* * *}$ \\
\hline & No & $36(11.8 \%)$ & $177(42.7 \%)$ & 1 & 1 \\
\hline \multirow{2}{*}{ Having TV } & Yes & $215(70.7 \%)$ & $160(38.6)$ & $3.85(2.80,5.28)$ & $1.99(1.19,3.30)^{* *}$ \\
\hline & No & $89(29.3)$ & $255(61.4)$ & 1 & 1 \\
\hline \multirow{2}{*}{ Pocket Money } & Yes & $68(22.4 \%)$ & $46(11.1 \%)$ & $2.31(1.44,3.48)$ & $0.73(0.42,1.25)$ \\
\hline & No & $236(77.6 \%)$ & $369(88.9 \%)$ & 1 & 1 \\
\hline \multirow{2}{*}{ Chat chewing } & Yes & $41(13.5 \%)$ & $10(2.4 \%)$ & $6.31(3.11,12.82)$ & $3.08(1.39,6.82)^{* *}$ \\
\hline & No & $263(86.5 \%)$ & $405(97.6 \%)$ & 1 & 1 \\
\hline \multirow{2}{*}{ Drinking alcohol } & Yes & $77(25.3 \%)$ & $49(11.8 \%)$ & $2.53(1.71,3.76)$ & $1.23(.64,2.37)$ \\
\hline & No & $277(74.7 \%)$ & $336(88.2 \%)$ & 1 & 1 \\
\hline \multirow{2}{*}{$\begin{array}{l}\text { Mothers educational } \\
\text { status }\end{array}$} & $<=$ primary & $185(60.9 \%)$ & $347(83.6(\%)$ & 1 & 1 \\
\hline & >=secondary & $119(39.1)$ & $68(16.4 \%)$ & $3.28(2.32,4.64)$ & $1.48(.96,2.28)$ \\
\hline \multirow{2}{*}{$\begin{array}{l}\text { Place of Primary } \\
\text { education }\end{array}$} & Urban & $212(69.7 \%)$ & $170(41 \%)$ & $3.32(2.43,4.54)$ & $0.96(0.57,1.60)$ \\
\hline & Rural & $92(30.3 \%)$ & $245(59 \%)$ & 1 & 1 \\
\hline
\end{tabular}

Table 4: Bivariate and multivariate logistic regressions of selected variables in relation to Utilization of EC among female high school students in Dodola town; January 2016.

\begin{tabular}{|c|c|c|c|c|c|}
\hline \multirow{2}{*}{\multicolumn{2}{|c|}{ Prediction variable }} & \multicolumn{2}{|c|}{ Ever used EC } & \multirow{3}{*}{$\begin{array}{c}\text { Crude OR(95\%CI) } \\
1\end{array}$} & \multirow{3}{*}{$\begin{array}{c}\text { Adjusted OR(95\%CI) } \\
1\end{array}$} \\
\hline & & \multirow{2}{*}{$\begin{array}{c}\text { Yes } \\
5(18.5 \%)\end{array}$} & \multirow{2}{*}{$\begin{array}{c}\text { no } \\
159(57.4 \%)\end{array}$} & & \\
\hline A oe in vears & $<=15$ & & & & \\
\hline Age ili yedis & $>15$ & $22(81.5 \%)$ & $118(42.6 \%)$ & $5.93(2.18,16.11)$ & $3.52(1.04,11.92)^{*}$ \\
\hline \multirow{2}{*}{ grade } & 9th & $7(25.9 \%)$ & $153(55.2 \%)$ & 1 & \\
\hline & 10th & $20(74.1 \%)$ & $124(44.8 \%)$ & $3.52(1.44,8.61)$ & $2.71(0.84,8.72)$ \\
\hline \multirow{2}{*}{ Having TV } & Yes & $24(88.9 \%)$ & $191(69 \%)$ & $3.6(1.06,12.28)$ & $1.55(0.27,8.79)$ \\
\hline & No & $3(11.1 \%)$ & $86(31 \%)$ & 1 & 1 \\
\hline \multirow{2}{*}{ Pocket Money } & Yes & $14(51.9 \%)$ & $54(19.5 \%)$ & $4.45(1.98,10.01)$ & $3.52(1.15,10.75)^{*}$ \\
\hline & No & $13(48.1 \%)$ & $223(80.5 \%)$ & 1 & 1 \\
\hline \multirow{2}{*}{ Drinking alcohol } & Yes & $12(44.4 \%)$ & $65(23.5 \%)$ & $2.61(1.16,5.86)$ & $1.08(0.31,3.72)$ \\
\hline & No & $15(55.6 \%)$ & $212(76.5 \%)$ & 1 & 1 \\
\hline \multirow{2}{*}{$\begin{array}{l}\text { Mothers educational } \\
\text { status }\end{array}$} & $<=$ primary & $6(22.2 \%)$ & $179(64.6 \%)$ & 1 & 1 \\
\hline & >=secondary & $21(77.8 \%)$ & $98(35.4 \%)$ & $6.39(2.45,16.37)$ & $4(1.32,12.09)^{*}$ \\
\hline \multirow{2}{*}{$\begin{array}{l}\text { Place of Primary } \\
\text { education }\end{array}$} & Urban & $23(85.2 \%)$ & $189(68.2 \%)$ & $2.68(0.89,7.97)$ & $0.54(0.10,2.81)$ \\
\hline & Rural & $4(14.8 \%)$ & $88(31.8 \%)$ & 1 & \\
\hline
\end{tabular}

\section{Discussion}

Unintended pregnancy that usually followed by unsafe abortion is a major reproductive health challenge in developing countries. This RH risk is higher among young females than adult women(4). Nevertheless, unwanted pregnancy resulting from unprotected sex can be prevented by the proper use of EC. The result of this study showed that $38.2 \%$ of the respondents were sexually active. Forty percent of sexually active students had history of pregnancy, which $83.6 \%$ of those pregnancies were unwanted and $58.7 \%$ of unwanted pregnancy resulted in unsafe abortion. Similar studies in Dessie and Mekele cities have showen lower prevalence of unintended pregnancy and unsafe abortion. High rate of unwanted pregnancy and unsafe abortion in this study than the above two studies may be due to high awareness and utilization of EC in those studies than current one which is $70 \%$ for Dessie and $90.3 \%$ for Mekele 
$[9,13]$. When compared to Dodola, the small rural town, the former two cities are with relative better positions both in health service accessibilities and information dissemination. This is more or less similar with studies of Addis Ababa University students $43.5 \%$ and high school students of Jimma town 40.5\% [11,14]. But it is lower than those studies conducted among tertiary students in Nigeria, college students of Dessie town and Adewa preparatory students $65.3 \%, 69.9 \% \& 64.48 \%$ respectively $[9,13,15]$. This discrepancy could be due to socio-demographic and difference in the education status of the study population.

This study revealed that, out of sexually active respondents only $9.8 \%$ of them were utilized emergency contraceptive methods. It is more or less similar with research done among youths of Parbat district, Nepal 8.34\% [10]. The finding of this study found to be lower than study conducted among Tertiary Students in Osun State, Southwestern Nigeria 32.6\%, Mekele preparatory school 53.5\% and Debre Markos University 18.4\% [13,15,16]. This might be due to the age and knowledge difference between university and high school students. Regarding determinant factors for the awareness and utilization of EC, the present study found that respondents whose age is greater than 15 years were about three times more likely to be aware and utilize EC compared to the age group of fifteen or less years. The finding is consistent with previous studies conducted in Addis Ababa, Mekele, Haramaya and Dessie which reported older age groups were more likely to be aware and practice EC when compared to younger age groups $[9,17,13-14]$. This might be due to younger youth may be less concerned about unwanted pregnancy and EC as they have not yet started or newly joining to sexual activity. The other possible explanation for this could be as age increases the education level and knowledge of sexual matters may increase.

This study found that respondents who had constant pocket money were more than three times more likely to practice EC than those who had no pocket money. This may be explained by having constant pocket money may help students to decide by themselves to buy and use EC if they faced unprotected sexual intercourse without the consent of others. Moreover, the more they are financial sufficient, the more that they have freedom to practice sex. This is in agreement with the study conducted in Hawassa University about the patterns of risky sexual practice among students [18].

\section{Conclusion and Recommendation}

The study finding showed low awareness and utilization of emergency contraceptive among female high school students. This may be among the reasons for high rate of unintended pregnancy and unsafe abortion among the study population. Awareness and utilization of female high school students on EC are affected by a range of circumstances. Given the high rate of unintended pregnancy and unsafe abortion reported by the study participants; the academic institution with the health sector should take measures that can increase awareness of students and ensure easy availability of EC at school level or adolescent and youth friendly clinic in the nearby.

\section{Acknowledgement}

We would like to thank school of public and environmental health, College of medicine and health sciences, Hawassa University for technical and financial support. We also would like to extend our gratitude to Dodola town education office, school principals, teachers, data collection facilitators, supervisors and study participants for their invaluable assistance and participation during the study period.

\section{Declaration}

\section{Ethical Considerations}

Ethical clearance was obtained from Hawassa University, College of Medicine and Health sciences Institutional Review Board (IRB). Official letter from Hawassa University was submitted to Dodola town educational office and high school's administrators. Informed verbal consent was obtained from the study participants after detail explanation of the purpose and the benefit of the study. Participants were informed that they have full right to discontinue or refuse to participate in the study at any time in the continuum of the data collection. They were also informed the anonymity of the study that by any means their participation in the study and response shall remain confidential.

\section{Consent for the Publication}

This manuscript is an extract from the MPH thesis. All ethical issues including communication of the finding to various stakeholders were properly communicated and their consents were obtained verbally.

\section{Data Availability}

The data for this study will be available when needed from the SPSS data pool.

\section{Declaration of Funding}

As mentioned earlier, this study was part of the fulfillment for the requirement for the master's degree in public health; small proportion of fund received from Hawassa University and the other portions of expenses were covered by me in support from my family and friend.

\section{Competing Interest}

The manuscript is part of an MPH thesis. It was the efforts of both authors mainly dedicated for academic purpose. Since the 
study expense is covered by the student himself, no external source put influence related to the outcome of the study. Moreover, neither the student nor the supervisor; had special interest in manipulating the outcome of the study except for the academic purpose.

\section{Authors' Contribution}

The manuscript is a joint effort of both authors. MS was responsible for conducting data collection, analysis and the write up. AA was responsible for revising transcription, analysis, editing and supervising all steps.

\section{Supporting Information}

1. Conceptual framework guided the study (Figure1)

2. 2, Schematic presentation of Sampling technique (Figure 2)

3. Table of socio-demographic characterstics of the respondents (Table 1)

4. Table of awareness and utilization of cmergency contraception by the respondents (Table 2)

5. Table of bivariate and multivariate logistic regressions of selected variables related to awareness towards EC by respondents (Table 3)

6. Table of bivariate and multivariate logistic regressions of selected variables related to utilzation ofEC by the respondents (Table 3).

\section{References}

1. Hossain, Sharif M I (2009) ECP Handbook Introducing and Mainstreaming the Provision of Emergency Contraceptive Pills in Developing Countries. Washington, DC: FRONTIERS Manual.

2. Parker C (2005) Adolescents and Emergency Contraceptive Pills in Developing Countries. family health international WP05-01.

3. Lloyd CB (2006) Schooling and Adolescent Reproductive Behavior in Developing Countries. Population Council.

4. Gilda S, Susheela S, Rubina H (2014) Intended and unitended pregnancies Worldwide in 2012 and recent trend. Studies In Family Planning 45(3): 301-14.

ISSN: 2574-1241

DOI: 10.26717/BJSTR.2021.38.006200

Abraham Alano. Biomed J Sci \& Tech Res

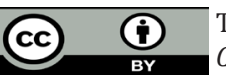

This work is licensed under Creative

Commons Attribution 4.0 License

Submission Link: https://biomedres.us/submit-manuscript.php
5. Mesce D, Clifton D (2011) Abortion facts and figer Washington DC: population reference Bureau.

6. De Bruyn M, Packer S (2004) Adolescents, unwanted pregnancy and abortion. IPAS.

7. (2012) CSA 2011 Ethiopia Demographic and Health Survey: Key Findings. USA: Minisrty of Health.

8. Kagashe GAB, Maregesi SM, Mashaka A (2013) Availability, Awareness, Attitude and Knowledge of Emergency Contraceptives in Dar Es Salaam Journal of pharmaceutical sciences and research 5(11): 4 .

9. Nibabe WT, Mgutshini T (2014) Emergency contraception amongst female college students - knowledge,attitude and practice. Afr JPrm Health Care Fam Med 6(1): 7.

10. Subedi S (2012) knowledge, attitude, and practice of emergency contraception among youths of parbat District. JHAS 2(1): 4.

11. Asmare T, Asmamaw DB, Temamen T, Addis AG, Yonas YA, et al. (2015) Assessment of Knowledge, Attitude and Practice Towards Emergency Contraceptive Methods Among Female Students in Seto Semero High School, Jimma Town, Southwest Ethiopia. Science Journal of Public Health 3(4): 13.

12. Miruts G, Yeman D, Abera K (2014) Factors associated with emergency contraceptive use among Female Preparatory Schools Students Adwa Town, Northern Ethiopia. IJPSR 5(10).

13. Solomon A, Feven Z, Fantahun M, Tadele E, Admassu A, et al. (2014) Assessment of Knowledge, Attitude and Practice among Regular Female School Students towards Emergency Contraceptives in Mekelle, Northern Ethiopia. International Journal of Pharma Sciences and Research (IJPSR) 5(11): 856-864.

14. Tamire W, Enqueselassie F (2007) Knowledge, attitude, and practice on emergency contraceptives among female university students in Addis Ababa, Ethiopia. Ethiop J Health Dev 21(2).

15. Fasanu AO, Adekanle AD, Adeniji AO, Akindele RA (2014) Emergency Contraception: Knowledge and Practices of Tertiary Students in Osun State, SouthWestern Nigeria. Gynecol Obstet (Sunnyvale) 4(196).

16. Abera H, Mokonnen M, Jara D (2014) Knowledge, Attitude, Utilization of Emergency Contraceptive and AssociatedFactors among Female Students of Debre Markos Higher Institutions, Northwest Ethiopia. Family Medicine \& Medical Science Research 3(4).

17. Desta B, Regassa N (2011) On Emergency Contraception among Female Studentsof Haramaya University, Ethiopia: Surveying the Level of Knowledge and Attitude. International Research Journals 2(4).

18. Berhan Y, Hailu D, Alano A (2011) Predictors of sexual-risk behavior and HIV- preventive practice among university students in Ethiopia. African Journal of HIV/ AIDS 10(3): 225-234.

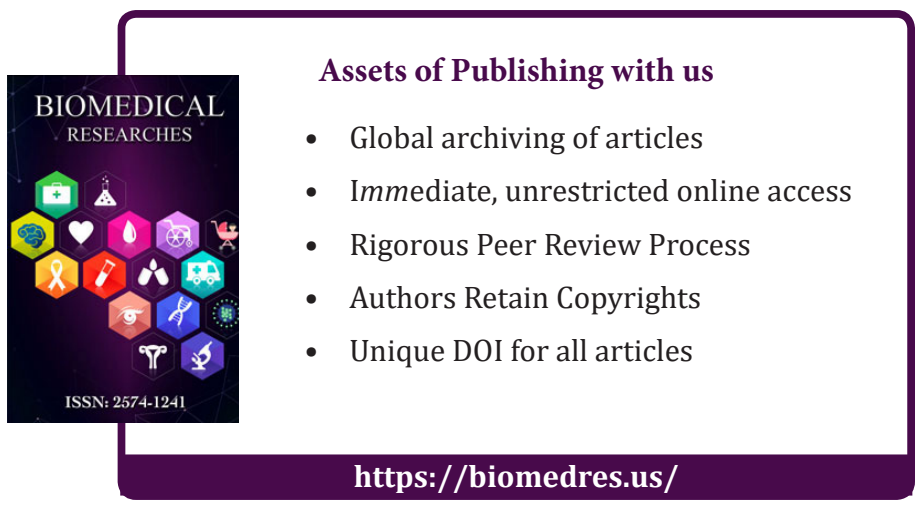

Copyright@ Abraham Alano | Biomed J Sci \& Tech Res | BJSTR. MS.ID.006200. 